University of Nebraska - Lincoln

DigitalCommons@University of Nebraska - Lincoln

Drought Mitigation Center Faculty Publications Drought -- National Drought Mitigation Center

2004

\title{
An Operational Agricultural Drought Risk Assessment Model for Nebraska, USA
}

Hong Wu

University of Nebraska - Lincoln, hwu2@unl.edu

Donald A. Wilhite

University of Nebraska - Lincoln, dwilhite2@unl.edu

Follow this and additional works at: https://digitalcommons.unl.edu/droughtfacpub

Part of the Climate Commons

Wu, Hong and Wilhite, Donald A., "An Operational Agricultural Drought Risk Assessment Model for Nebraska, USA" (2004). Drought Mitigation Center Faculty Publications. 7.

https://digitalcommons.unl.edu/droughtfacpub/7

This Article is brought to you for free and open access by the Drought - National Drought Mitigation Center at DigitalCommons@University of Nebraska - Lincoln. It has been accepted for inclusion in Drought Mitigation Center Faculty Publications by an authorized administrator of DigitalCommons@University of Nebraska - Lincoln. 


\title{
An Operational Agricultural Drought Risk Assessment Model for Nebraska, USA
}

\author{
Hong Wu and Donald A. Wilhite \\ National Drought Mitigation Center, University of Nebraska-Lincoln, \\ Lincoln, Nebraska, 68583-0728, USA \\ Corresponding author - H. Wu, hwu2@unl.edu
}

\begin{abstract}
Drought is a common occurrence in Nebraska and agriculture is the primary economic sector affected. Because of repeated and widespread severe drought impacts, more emphasis on drought risk management is warranted. This study develops an agricultural drought risk assessment model using multivariate techniques. The model is specific to corn and soybeans and is able to assess realtime agricultural drought risk associated with crop yield losses at critical phenological stages prior to and during the growing season. The assessment results are presented in a Geographic Information System to provide a better visualization. This model provides information in a timely manner about potential agricultural drought risks on dryland crop yield to decision makers ranging from agricultural producers to policy makers from local to national levels.
\end{abstract}

Keywords: risk assessment, agricultural drought, discriminant analysis, Standardized Precipitation Index, Crop-Specific Drought Index

\section{Introduction}

It is more difficult to detect the emergence of droughts compared to other natural hazards because of drought's unique characteristics: its slow-onset, the absence of a universally accepted definition for drought, and its non-structural impacts (Wilhite, 1992). In addition, it is more difficult to assess drought impacts in various sectors because the impacts can be regional or local. Furthermore, droughts may linger for a long time (a year or more), or just last for a very short time (several weeks). If a shortterm drought occurs at critical crop growth stages, the impacts on agriculture may be severe (Kulshreshtha and Klein, 1989). Some researchers found that the impact of droughts on agriculture is neither immediate nor easily measured (Kumar and Panu, 1997).

Nebraska has experienced numerous droughts with varying magnitude, duration and extent since precipitation was first recorded in the state. Certainly, drought is a common occurrence in the state and agriculture is the primary economic sector affected (The State of Nebraska Drought Mitigation and Response Plan, 2002). The historical records reveal there is no regularity of drought cycles in Nebraska, and drought 
can be both frequent and severe. Therefore, it is certain that drought will occur again, but its occurrence cannot be predicted (Agriculture Atlas of Nebraska, 1977).

Because of repeated and widespread severe drought impacts in Nebraska, more emphasis on drought risk management is warranted (The State of Nebraska Drought Mitigation and Response Plan, 2002). Nebraska's Climate Assessment Response Committee (CARC) was established by the Nebraska Legislature in 1991. As a part of the CARC drought mitigation and response plan, a Risk Assessment Committee was established "to assess the vulnerability to and likely impacts of extreme climatic events, particularly drought, on Nebraska's primary economic, environmental and social sectors" (CARC, 2002). In support of the Risk Assessment Committee's objectives, a methodology was developed for assessing vulnerability to agricultural drought in Nebraska (Wilhelmi, 1999; Wilhelmi and Wilhite, 2002) using four criteria: (1) probability of seasonal crop moisture deficiency; (2) soil root zone available water-holding capacity; (3) land-use types; and (4) access to irrigation. The goal of the map illustrating agricultural drought vulnerability presented in the study was to improve decision makers' understanding of the complex set of factors influencing drought risk. With improved understanding, agricultural practices could be adjusted based on regional vulnerabilities.

To improve drought risk management, identifying the causes of drought vulnerability in a specific region is an important step. But this step alone is not sufficient. The key factors used by Wilhelmi (1999) and Wilhelmi and Wilhite (2002) to define vulnerability were relatively static. Also, this vulnerability analysis was not crop-specific. For example, seasonal crop moisture deficiency estimated in the study was based on the combination of various crops through crop-area-weighting. The weather prior to and during the crop growing season differs each year, leading to variable drought impacts on agriculture from year to year, and from one crop to another. To be most effective, drought risk assessment should also be based on actual weather information that influences crop growth (Dietz et al., 1998) and be crop-specific.

This study contributes to the research on agricultural risk assessment by developing an operational model in Nebraska. The premise of this study is that agricultural drought risk on a specific crop yield is linked to the moisture supplies prior to and during the growing season. The proposed model focuses on detecting potential agricultural drought risk before the crop is planted and at critical phenological stages during the growing season using real-time weather information. This model will provide policy makers with sufficient time to implement strategies to reduce risk potential. This information could also be used by farmers to make decisions on whether to purchase crop insurance (Luo et al., 1994).

\section{Literature Review}

Numerous factors impose risks on agricultural production or yield, including droughts, floods, pests, labor shortage, price fluctuations and political factors (Dietz 
et al., 1998; Thompson and Powell, 1998). Among these factors, the effect of weather conditions on agricultural production is significant. For instance, poor weather conditions caused crop failure in the United States in 1974, and in other parts of the world in the early 1970's (Pitter, 1977). The 1988 drought, the most costly weather disaster in United States history with damages estimated at $\$ 40$ billion, seriously affected corn and soybean production. According to the statistics, national corn production was reduced by $45 \%$ from the 1985-87 average, and soybean production dropped 26\%. Agricultural losses were estimated at \$15.6 billion (Reibsame et al., 1991; Sundt, 2002).

A close relationship exists between crop yield and water stress, and therefore, crop yield is a reliable indictor of agricultural drought (Kumar and Panu, 1997). Crop yield response to water stress is a critical factor when assessing and predicting agricultural drought risk. Wilhite and Neild (1982) defined agricultural drought in terms of plant response by using the degree of departure from the expected yield as an indicator of weather conditions for a given year on the assumption that crops are good integrators of weather and their response provides a reliable tool for measuring drought. However, the relationship between crop yield and water stress is variable from crop to crop, making assessment and prediction complicated. Duchon (1986) indicated that crop yield was the outcome of both natural and managed factors. The natural factors include soil type, pests, diseases, stored soil moisture and daily weather during the growing season. The management factors include plant variety, plant density, sowing date, fertilization, irrigation and chemical treatment for pests and diseases. To eliminate some of this complexity, emphasis is often placed on a single crop grown homogeneously over the region of interest (Kumar and Panu, 1997).

The response of yield is dependent on the environmental conditions during the growing season as well as during antecedent periods. Thus, monthly total precipitation for the preseason (October-March) period and April through August was included in the model established by Starr and Kostrow (1978) for estimating the response of spring wheat yield to anomalous climate sequences. The crop/weather models used by Thompson (1988) investigated the effects of climate change and weather variability on the yields of corn and soybeans. The Thompson study used six weather variables: preseason precipitation (the total from September through June), June temperature, July rainfall and temperature, and August rainfall and temperature to estimate crop yields. Walker (1989) developed a model using pre-growing season and growing season weather data and only near real-time weather variables were used in the model. The results showed that the model provided a realistic and useful pre-harvest yield forecast. The model that Mjelde and Penson Jr. (2000) presented to demonstrate the impact of the timing of good and poor crop years on financial conditions in the Corn Belt region also defined previous fall and early spring as part of the production season.

Additionally, the length of time scale of the variables employed in the agricultural drought risk assessment is critical. Pochop et al. (1975) developed a model to assess 
the potential effects of weather modification on agricultural production in the Great Plains area of Wyoming. It was found that the crop-weather function was sensitive to short-period (i.e. days, weeks) weather events because even equal amounts of precipitation, distributed at different times during crop growing season, may have different effects on the crop. Statistical analysis was performed to determine the climatic factors that were most important to winter wheat production. The variables used in the model included weekly rainfall total during the growing season, an 8-week rainfall for the previous fall/winter period, a 17-week rainfall total beginning the growing season of the previous year and weekly temperature means from various times. Dietz et al. (1998) suggested that weekly rainfall should be investigated in drought risk assessment if data allows, because the variability of the rainfall, its distribution and insecure start of the rainy season present high risks on dryland crops.

The weather conditions at a given time will have differential effects on crop yield, either beneficial or detrimental, depending on plant types and growth stage in the life cycle at that time (Denmead and Shaw, 1960; Starr and Kostrow, 1978). Each crop growth stage has its own sensitivity to soil moisture stress. It was shown that water stress prior to silking had an indirect effect on corn yield, while stress at silking had a more direct effect. Easterling et al. (1988) found that mild drought during the spring cultivating and planting period may be a positive stimulus to corn yields in Illinois. Excess moisture during early plant growth may limit vertical penetration of the root system. As a result, roots cannot reach moisture stored deeper in the soil and are likely to experience stress when it becomes dry during post-emergence growing stage. Hill et al. (1979) also indicated that water stress contributed differently to soybean yield for different growth periods, and developed a model that determines soybean yield as a function of moisture availability during each period of growth. Thompson (1988) found that corn yields were more affected by July weather, while soybean yield was more affected by August weather. Pochop et al. (1975) concluded that the greatest benefit of added rainfall to increased winter wheat production was during the middle portion of the growing season, while the benefits were relatively negligible in the early season and negative in the late season. Nullet and Giambelluca (1988) indicated that it would minimize the risk of drought damage on crops if risk analysis of seasonal agricultural drought was combined with crop growth stage information.

A common tool used in agricultural drought risk assessment is the drought index, which is applied either as an individual index or in a composite with other indices. For example, Easterling et al. (1988) combined the Moisture Anomaly Index (MAI) and Palmer Drought Severity Index (PDSI) values to reflect crop moisture sensitivities. Thompson and Wehmanen (1979) employed Green Index Number (GIN) derived from remotely sensed data to detect agricultural vegetative water stress. The GIN is defined as the percent of pixels in a segment with a green number greater than 15. Walker (1989) designed a physiological-based composite drought index as a function of the balance between cumulative water supply and transpiration demand. 
McKee et al. (1993) developed the Standardized Precipitation Index (SPI), which only requires data for precipitation, based on the concept that precipitation deficits over varying periods or timescales influence ground water, reservoir storage, soil moisture, snowpack, and streamflow. Furthermore, unlike other indices, the SPI was tested and diagnosed carefully and extensively for about 1200 stations in the United States (Redmond, 2002). The SPI is employed to monitor the current status of droughts in Colorado by the Colorado Climate Center (CCC, 2003) and for the United States by the Western Regional Climate Center (WRCC, 2003) and National Drought Mitigation Center (NDMC, 2003). Over 40 countries are using the SPI for drought monitoring and drought research (D. A. Wilhite, personal communication). Furthermore, researchers demonstrated that the SPI is a good tool in detecting and monitoring the severe drought event that occurred in the southern Great Plains and the southwestern United States in 1996 (Hayes et al., 1999).

An important characteristic of the SPI is that it can be used to monitor dry and wet periods over a wide spectrum of time scales, allowing users the opportunity to choose the time scale most appropriate for their particular application to compute the SPI (Edwards and McKee, 1997). Originally, the time scale of the SPI was a monthly step ranging from 1 to 72 months. For an agricultural drought risk study, a monthly time scale is too long because crop growth stages are generally based on days or weeks. Recently, scientists in the Computer Science and Engineering Department of University of Nebraska-Lincoln developed a program in collaboration with the NDMC and the High Plains Regional Climate Center (HPRCC) to calculate a weekly SPI. As mentioned by McKee et al. (1993), agricultural droughts typically have a much shorter time scale than hydrological droughts. Therefore, the weekly SPI should be more appropriate in agricultural drought risk studies than the monthly value.

Meyer et al. (1993a) developed a Crop-Specific Drought Index (CSDI) by creatively integrating four critical factors: crop specificity, soil specificity, the ratio of water consumed by the crop to that consumed potentially, and the growth stage during which the stress occurs. The CSDI was originally developed for corn (Meyer et al., 1993a), and then extended to soybeans (Meyer and Hubbard, 1995), wheat (Xu, 1996), and sorghum (Camargo and Hubbard, 1999).

The definition of CSDI is based on the ratio of actual evapotranspiration to potential evapotranspiration:

$$
\mathrm{CSDI}_{\mathrm{pred}}=\prod_{i=1}^{n}\left(\frac{\sum \mathrm{ET}_{\mathrm{calc}}}{\sum \mathrm{ET}_{\mathrm{pc}}}\right)_{i}^{\lambda_{i}}=\frac{\mathrm{Y}_{\mathrm{pred}}}{\mathrm{Y}_{\mathrm{pot}}}
$$

where $\mathrm{ET}_{\mathrm{calc}}$ and $\mathrm{ET}_{\mathrm{pc}}$ are the calculated and the potential evapotranspiration (mm) for the crop at each growth period; $n$ the number of periods chosen to represent the crop's growth cycle; $\lambda_{i}$ the relative sensitivity of the crop to moisture stress during the $i$ th period of growth; $Y_{\text {pred }}$ and $Y_{\text {pot }}$ are predicted and potential yields. Equation 
(1) can also predict yield by computing the product of predicted CSDI and potential yield.

Results showed that the CSDI performed well over a range of climatic conditions and geographical locations in the United States. Advantages were found in using the CSDI in drought monitoring and assessment over other drought indices such as PDSI and Crop Moisture Index (CMI) (Meyer et al., 1993b). First, the CSDI is crop specific. Thus, the CSDI values can be directly linked to drought impact on the specific crops of interest. Also, the impact of drought on crop yield can be assessed at critical stages during the growing season. Therefore, the CSDI is a good surrogate index for agricultural drought potential.

Each drought index is designed for specific conditions and for a specified purpose. No single drought index can work in all circumstances. There is a tendency to evaluate drought severity using several indices or variables. For instance, Colorado is monitoring its water resources using a combination of the SPI, Surface Water Supply Index (SWSI) and Palmer indices (Hayes et al., 2000). Wilhite (2000) pointed out that it is important to use appropriate and reliable drought indices in decision making. Consulting more than one index before making a decision, therefore, is necessary and critical. To better track and assess the severity of droughts, the scientists in the NDMC, Climatic Prediction Center (CPC) and U.S. Department of Agriculture (USDA) developed an integrated Drought Monitor product. This system is a synthesis of several different scientific drought indices including the Palmer Drought Index, CMI, CPC Soil Moisture Model, USGS Daily Stream-flow, Percent of Normal Precipitation, USDA/NASS Topsoil Moisture, and a remotely sensed Satellite Vegetation Health Index (NDMC/NOAA/USDA Drought Monitor, 2003; Svoboda et al. 2002).

A Geographic Information System (GIS) allows spatial analysis and complex overlays of data on the location, topology and attributes of spatial objects (Ger-main, 1996). GIS has the capability to generate an improved agricultural drought monitoring system that integrates various factors that contribute to drought impacts, and present the results in a timely and appropriate manner for policy makers (Lourens et al. 1997, de Jager et al., 1998, and de Jager et al., 2000). With a GIS-based map of drought vulnerability, it is easier for policy makers, agricultural producers and others to visualize the hazard and communicate with each other (Wilhelmi, 1999; Wilhelmi and Wilhite, 2002).

\section{Model Development}

Based on the literature review, the proposed model was developed to possess the following characteristics. First, the model needed to be crop-specific. The model was developed specifically for corn and soybeans because these two are the main crops in Nebraska and they also exhibit different sensitivities to water stress (Wilhite, 1982). Second, the model assessed drought risks at critical phenological stages during crop 
development, providing risk information in a timely manner. Third, drought risk was associated with crop yield losses. Fourth, weekly weather information during the growing season as well as during antecedent periods were considered as factors contributing to the risks. Fifth, the model used existing drought indices as moisture supply indicators before and during the growing season. Sixth, all the studies were undertaken at a county-level resolution. Finally, the assessment results were presented in a GIS to provide a better visualization.

It is not the purpose of this article to introduce the procedures of the model development in detail. For more details regarding to the methodology, see Wu (2002). The main aim of this article is to present the characteristics of the newly-developed model in agricultural risk assessment.

\subsection{Data Preparation}

The fundamental goal of the proposed model was to establish a predictable relationship between moisture supplies prior to and during the growing season and the agricultural impacts of the moisture supplies on a specific crop at critical phenological stages.

The indicators of the moisture supplies prior to and during the growing season were represented by two existing drought indices. The SPI was chosen because it is a precipitation-only index and can be calculated for multiple time scales. The flexible time scales of the SPI make it easier to compute the index matching a crop's phenological cycle while providing the moisture supply status along with crop growth stages. The CSDI was chosen as a partner to the SPI because the CSDI links specific crop responses to drought, making it possible to be a crop-specific risk assessment model. For details on the calculation of the SPI and CSDI, see Edwards and McKee (1997) and Meyer et al. (1993a). All the weather data to calculate the indices were obtained from the HPRCC (2003).

The SPI values at high frequency time scales reflect moisture supply more precisely than that with lower frequency. As a result, the time scales of the SPI that were included in the study were: 1-, 2-, 3-, 4-, 5-, 6-, 7-, 8-, 9-, 10-, 11-, 12-, 14-, 16, 18-, 20-, 22-, 24-, 26-, 28-, 30-, 32-, 36-, 40-, 44-, and 52-weeks. Then the 26 individual SPI values were combined into 4 variables by summing the SPI values at very short, short, medium and long time scales because the impact of drought on agriculture is an accumulated consequence and the SPI sums are measurements of accumulated magnitude of the drought. In addition, Principal Components Analysis (PCA) was performed on the 26 SPI values to extract the first three PCs, which account for most of the variance of the original 26 SPI values. The four SPI sums, as well as the first three PCs, were determined as the general feature variables for further analysis in the study, indicating moisture supplies before and during the crop growing season. The final feature variables used for each critical stage were determined by the contributions of the variables in indicating impacts of water stress on crop yield. For a specific stage, the feature variables may change because some vari- 
ables from the previous stages may be retained, variables from the current stage may be added and redundant variables may be removed. Tables I and II show the lists of the variables selected by statistical approaches for each stage for corn and soybeans, respectively.

The indicator of agricultural drought risk because of limited moisture supplies was represented by the residuals of the detrended yield because the residual variation reflects the effects of weather on yield (Dennett et al., 1980; da Mota, 1983), and the residuals amplify yield departures from normal, making the variability of yield more obvious. Although corn and soybeans are planted in most of Nebraska's counties, this study concentrated on the leading production counties, which were identified as those that consistently contained $90 \%$ of the total acreage harvested for dryland corn or soybeans during 1971-2000. The non-irrigated yields of corn for grain and soybeans of each leading county in Nebraska were obtained from the online database of the National Agricultural Statistics Service (NASS) of the USDA (2003). A positive yield residual means the yield is above the $30-y r$ average yield, while a negative residual means the yield is below the average yield. The bigger the absolute value of yield residual, the bigger the departure from the average yield. A year was identified as a high drought risk year when the corresponding crop yield residual was smaller than -0.5 . Otherwise, the year was a low risk year.

The critical phenological stages to make the risk assessments were determined as follows. The combined phenological growth periods used in the CSDI for corn included vegetative, ovule, reproduction, and ripening, and for soybeans included vegetative, blooming, pod formation, pod fill, and ripening. Besides these periods defined in the CSDI, this study defined one more period, pre-plant period, for both corn and soybeans. The pre-plant period was the 1-yr period before crop emergence. In this paper, pre-planting denotes the period before corn emergence, stage 1 denotes vegetative period, stage 2 ovule, stage 3 reproduction, and stage 4 ripening. The same case holds for soybeans, using pre-planting and stages 1 through 5 to denote the period before soybean emergence and the five periods.

\subsection{Rationale of Model Development}

One of the tasks of this study was to establish a predictable relationship between the indicators of moisture supply represented by the SUMs and PCs of the SPI and CSDI and the indicator of risks represented by two categorical yield residual variables: low and high risk year. From a statistical point of view, this is the case of categorical dependent variables (i.e. low and high risk year) and a set of independent variables (e.g., the SUMs and PCs of the SPI and CSDI). The goal is to assign a year of interest to one of the two previously defined groups in terms of drought risk according to the known SPI and CSDI. Discriminant analysis is a statistical technique for classifying individuals or objects into mutually exclusive and exhaustive groups on the basis of a set of independent variables (Johnson and Wichern, 1998). 
Table I. Feature variables used in the discriminant analysis at each critical phenological stage for corn

\begin{tabular}{|c|c|c|c|c|c|}
\hline Variables & $\begin{array}{l}\text { Pre-planting } \\
\text { (17th week) }\end{array}$ & $\begin{array}{l}\text { Stage1 } \\
\text { (26th week) }\end{array}$ & $\begin{array}{l}\text { Stage2 } \\
\text { (29th week) }\end{array}$ & $\begin{array}{l}\text { Stage3 } \\
\text { (33rd week) }\end{array}$ & $\begin{array}{l}\text { Stage4 } \\
\text { (39th week) }\end{array}$ \\
\hline
\end{tabular}

SUM1 of 17th week's SPI

SUM2 of 17th week's SPI

SUM3 of 17th week's SPI

SUM4 of 17th week's SPI

SUM1 of 26th week's SPI

SUM2 of 26th week's SPI

SUM3 of 26th week's SPI

SUM4 of 26th week's SPI

SUM1 of 29th week's SPI

SUM2 of 29th week's SPI

SUM3 of 29th week's SPI

SUM4 of 29th week's SPI

SUM1 of 33rd week's SPI

SUM2 of 33rd week's SPI

SUM3 of 33rd week's SPI

SUM4 of 33rd week's SPI

SUM1 of 39th week's SPI

SUM2 of 39th week's SPI

SUM3 of 39th week's SPI

SUM4 of 39th week's SPI

First PC of 17th week

Second PC of 17 th week

Third PC of 17 th week

First PC of 26th week

Second PC of 26th week

Third PC of 26th week

First PC of 29th week

Second PC of 29th week

$\sqrt{ }$

$\sqrt{ }$

$\sqrt{ }$
$\sqrt{ }$

Third PC of 29th week

First PC of 33rd week

Second PC of 33rd week

Third PC of 33rd week

First PC of 39th week

Second PC of 39th week

Third PC of 39th week

CSDI-stage1

CSDI-stage2

CSDI-stage3

CSDI-stage4
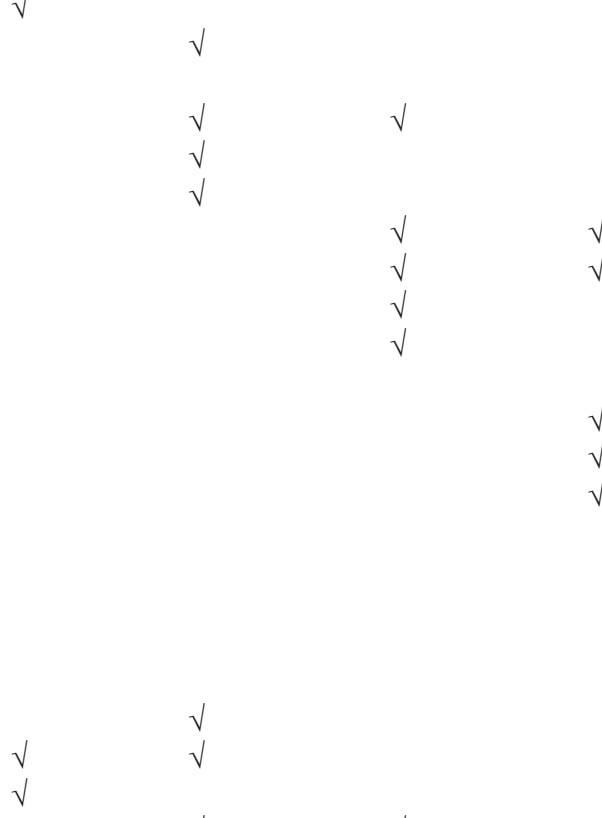

$\sqrt{ }$
$\sqrt{ }$
$\sqrt{ }$
$\sqrt{ }$
$\sqrt{ }$

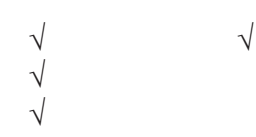

SUM1 of 17th week's SPI denotes the sum of the 17th week's SPI values at 1-, 2-, 3-and 4-week. SUM2 of 17 th week's SPI denotes the sum of the 17th week's SPI values at 5-, 6-, 7-, 8-, 9-, and 10-week. SUM3 of 17th week's SPI denotes the sum of the 17th week's SPI values at 11-, 12, 14-, 16-, 18-, 20-, 22-, 24-, 26-, 28-, 30-and 32-week. SUM4 of 17th week's SPI denotes the sum of the 17th week's SPI values at 36-, 40-, 44, and 52-week. First PC of 17th week denotes the first principal component of the 17th week's SPI. Second PC of 17th week denotes the second principal component of the 17th week's SPI, and so on. 
Table II. Feature variables used in the discriminant analysis at each critical phenological stage for soybeans

\begin{tabular}{|c|c|c|c|c|c|c|}
\hline Variables & $\begin{array}{l}\text { Pre-planting } \\
\text { (19th week) }\end{array}$ & $\begin{array}{c}\text { Stage1 } \\
\text { (26th week) }\end{array}$ & $\begin{array}{l}\text { Stage2 } \\
\text { (28th week) }\end{array}$ & $\begin{array}{l}\text { Stage3 } \\
\text { (32nd week) }\end{array}$ & $\begin{array}{l}\text { Stage4 } \\
\text { (35th week) }\end{array}$ & $\begin{array}{l}\text { Stage5 } \\
\text { (40th week) }\end{array}$ \\
\hline SUM1 of 19th week's SPI & $\sqrt{ }$ & $\sqrt{ }$ & $\sqrt{ }$ & $\sqrt{ }$ & $\sqrt{ }$ & \\
\hline SUM2 of 19th week's SPI & $\sqrt{ }$ & $\sqrt{ }$ & $\sqrt{ }$ & & $\sqrt{ }$ & \\
\hline SUM3 of 19th week's SPI & $\sqrt{ }$ & $\sqrt{ }$ & & & $\sqrt{ }$ & \\
\hline SUM4 of 19th week's SPI & $\sqrt{ }$ & $\sqrt{ }$ & & & & \\
\hline SUM1 of 26th week's SPI & & & & $\sqrt{ }$ & & \\
\hline SUM2 of 26th week's SPI & & & & $\sqrt{ }$ & $\sqrt{ }$ & \\
\hline SUM3 of 26th week's SPI & & & $\sqrt{ }$ & & & \\
\hline SUM4 of 26th week's SPI & & & $\sqrt{ }$ & $\sqrt{ }$ & & \\
\hline SUM1 of 28th week's SPI & & & $\sqrt{ }$ & $\sqrt{ }$ & & \\
\hline SUM2 of 28th week's SPI & & & $\sqrt{ }$ & $\sqrt{ }$ & $\sqrt{ }$ & \\
\hline SUM3 of 28th week's SPI & & & $\sqrt{ }$ & & $\sqrt{ }$ & \\
\hline SUM4 of 28th week's SPI & & & $\sqrt{ }$ & & $\sqrt{ }$ & \\
\hline SUM1 of 32nd week's SPI & & & & $\sqrt{ }$ & $\sqrt{ }$ & \\
\hline SUM2 of 32nd week's SPI & & & & & & \\
\hline SUM3 of 32nd week's SPI & & & & $\sqrt{ }$ & & \\
\hline SUM4 of 32nd week's SPI & & & & & & \\
\hline SUM1 of 35th week's SPI & & & & & & $\sqrt{ }$ \\
\hline SUM2 of 35th week's SPI & & & & & & $\sqrt{ }$ \\
\hline SUM3 of 35th week's SPI & & & & & & \\
\hline SUM4 of 35th week's SPI & & & & & $\sqrt{ }$ & \\
\hline SUM1 of 40th week's SPI & & & & & & \\
\hline SUM2 of 40th week's SPI & & & & & & \\
\hline SUM3 of 40th week's SPI & & & & & & \\
\hline SUM4 of 40th week's SPI & & & & & & $\sqrt{ }$ \\
\hline First PC of 19th week & $\sqrt{ }$ & $\sqrt{ }$ & $\sqrt{ }$ & & & \\
\hline Second PC of 19th week & $\sqrt{ }$ & & $\sqrt{ }$ & $\sqrt{ }$ & $\sqrt{ }$ & \\
\hline Third PC of 19th week & $\sqrt{ }$ & $\sqrt{ }$ & $\sqrt{ }$ & $\sqrt{ }$ & $\sqrt{ }$ & \\
\hline First PC of 26th week & & $\sqrt{ }$ & & & & \\
\hline Second PC of 26th week & & $\sqrt{ }$ & $\sqrt{ }$ & $\sqrt{ }$ & & \\
\hline Third PC of 26th week & & & & & $\sqrt{ }$ & \\
\hline First PC of 28th week & & & & $\sqrt{ }$ & & $\sqrt{ }$ \\
\hline Second PC of 28th week & & & & $\sqrt{ }$ & & \\
\hline Third PC of 28th week & & & & & & \\
\hline First PC of 32nd week & & & & $\sqrt{ }$ & & $\sqrt{ }$ \\
\hline Second PC of 32nd week & & & & $\sqrt{ }$ & & \\
\hline Third PC of 32nd week & & & & $\sqrt{ }$ & & \\
\hline First PC of 35th week & & & & & $\sqrt{ }$ & $\sqrt{ }$ \\
\hline Second PC of 35th week & & & & & $\sqrt{ }$ & \\
\hline Third PC of 35th week & & & & & $\sqrt{ }$ & \\
\hline First PC of 40th week & & & & & & $\sqrt{ }$ \\
\hline Second PC of 40th week & & & & & & $\sqrt{ }$ \\
\hline Third PC of 40th week & & & & & & \\
\hline CSDI-stage1 & & & & & & \\
\hline CSDI-stage2 & & & $\sqrt{ }$ & $\sqrt{ }$ & $\sqrt{ }$ & \\
\hline CSDI-stage3 & & & & $\sqrt{ }$ & $\sqrt{ }$ & \\
\hline CSDI-stage4 & & & & & $\sqrt{ }$ & \\
\hline CSDI-stage5 & & & & & & $\sqrt{v}$ \\
\hline
\end{tabular}

The previous definitions hold. 
Two discriminant analysis techniques were employed: one was the canonical discriminant analysis, which helped visualize the possibility to discriminate the observations belonging to the high risk group from those belonging to the low risk group on the basis of the feature variables derived from the SPI and CSDI for both corn and soybeans at each selected phenological time stage; the other technique was the classificatory discriminant analysis, through which a classification rule was established to classify observations into the two predefined groups on the basis of the feature variables.

The classificatory discriminant analysis generated a risk-discriminant model at each stage. For example, the risk-discriminant model for corn at pre-planting generated by the classificatory discriminant analysis was:

$$
D=\beta_{1}\left(\mathrm{SUM}_{17}\right)+\beta_{2}\left(\mathrm{SUM}_{17}+\beta_{3}\left(\mathrm{SUM}_{17}\right)+\beta_{6}\left(\mathrm{PC}_{17}\right)+\beta_{7}\left(\mathrm{PC}_{17}\right)+\mathrm{C}_{,}(2)\right.
$$

where $D$ is the discriminant score, $\mathrm{SUM} 1_{17}$ is SUM1 of 17 th week, $\mathrm{PC}_{17}$ is the second PC of 17th week's SPI values, and so on; $\beta$ is the discriminant function weight, and $C$ is the intercept. For a year of interest, a discriminant score $D$ was computed by the model. The year of interest was grouped into the high risk year classification if $D$ was smaller than zero, otherwise the year was grouped into the low risk year classification.

\section{Validation of the Model}

The performance of the risk-discriminant model was validated by estimating accurate rates with independent data. The accurate rate is the probability of correct classification. The validation of the model was accomplished in three ways:

First, the risk-discriminant model was derived by part of the data from the leading counties for both corn and soybeans during 1971-2000. Then the model was validated by the data of the remaining counties in the same period.

Second, the model was derived for both corn and soybeans using the data during 1971-1995 and validated using the data during 1996-2000.

Third, the model was validated by assessing drought risks for corn in a few severe drought years $(1974,1980,1988)$ and a dry-wet mixed year $(2001)$.

\section{Results}

The canonical and classificatory discriminant analysis described above were performed for each of the leading counties and the derived risk-discriminant model was validated using three kinds of training datasets and test datasets. The results are presented below.

Figures 1 and 2 show the plots of canonical variables of each stage for both corn and soybeans, respectively. The first and second canonical variables are the linear 

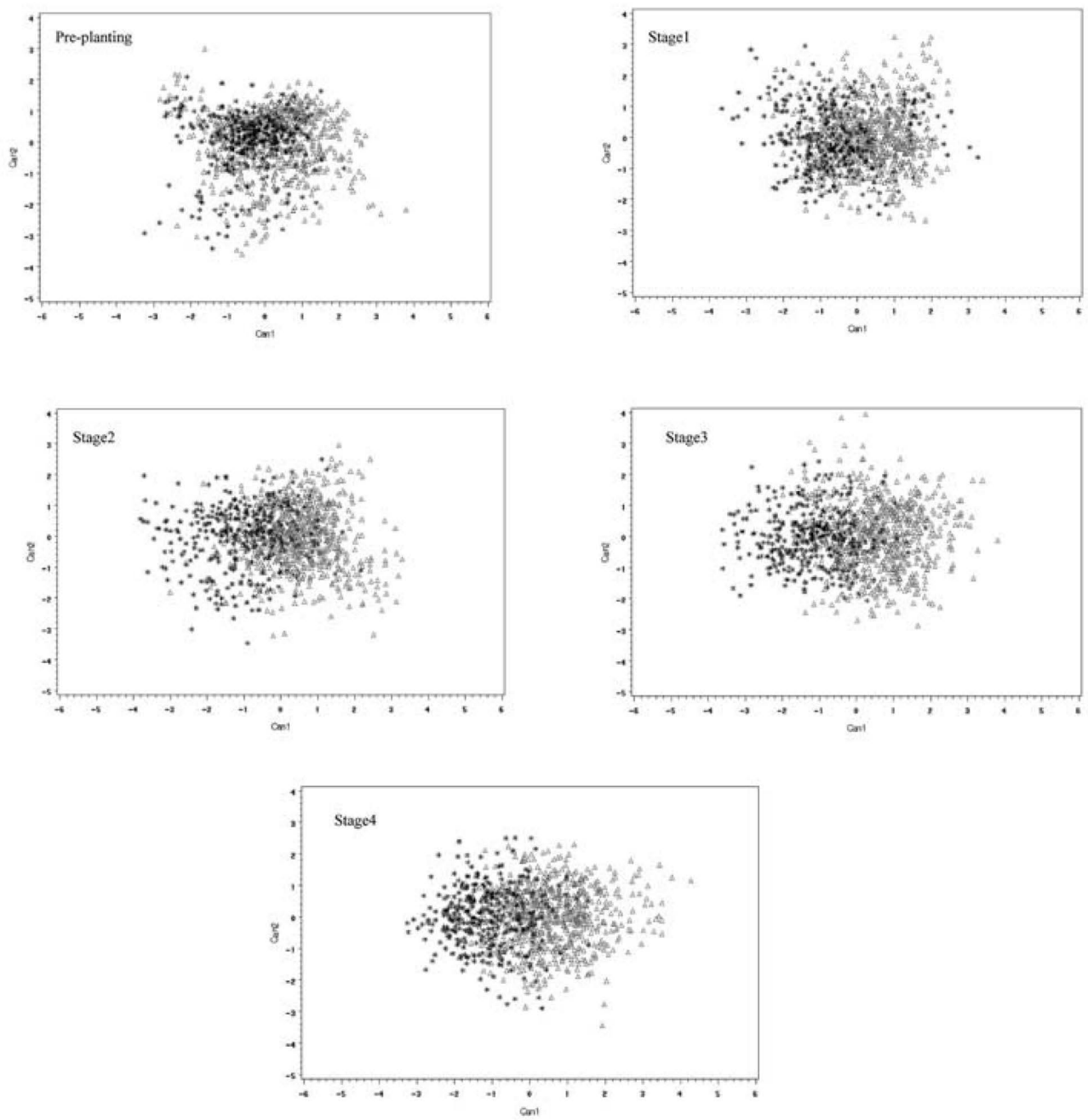

Figure 1. Plots of the first vs. second canonical variables at pre-planting through stage 4 for corn. Black stars denote the high risk year, gray triangles denote the low risk year. Can1 is the first canonical variable. Can2 is the second canonical variable.

combinations of the feature variables that have the highest possible multiple correlation with the groups. As can be seen, for corn at earlier stages, the first and second canonical variables do not separate the observations from the two groups effectively. Overlap between the low and high risk groups is significant. As the growth period progresses, however, the separation between the two groups becomes more obvious. The observations from the high risk group mostly cluster on the left side of the plots, while the observations from the low risk group cluster on the right side. For soybeans, the tendency of separation becomes clearer from stage 3 on. 

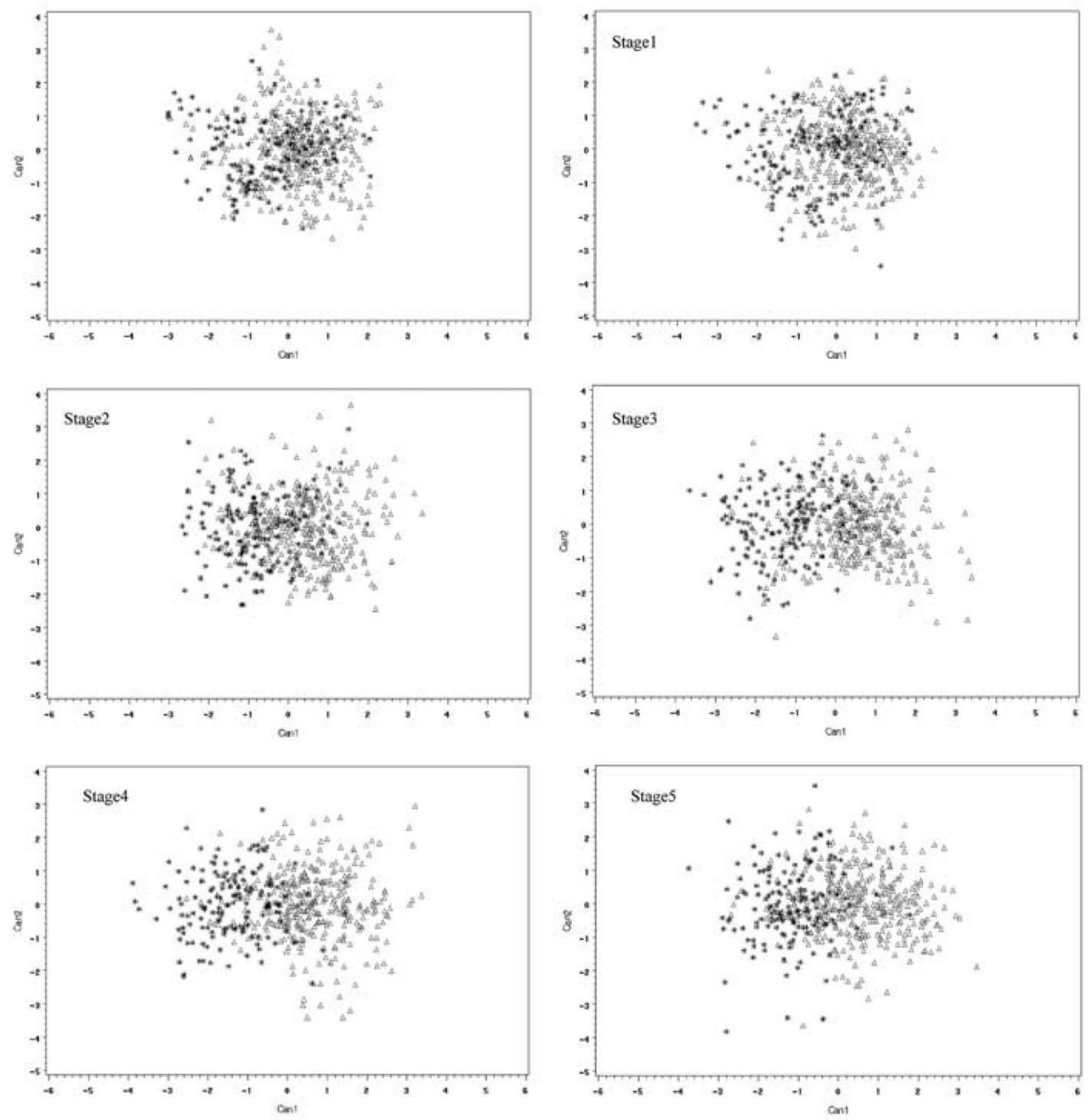

Figure 2. Plots of the first vs. second canonical variables at pre-planting through stage 5 for soybean. Black stars denote the high risk year, gray triangles denote the low risk year. Can1 is the first canonical variable. Can2 is the second canonical variable.

Therefore, based on the canonical discriminant analysis, it was possible to discriminate the high risk group from the low risk group on the basis of the feature variables derived from the SPI and CSDI for both corn and soybeans, especially during later stages. Through the classificatory discriminant analysis, a classification rule was established and applied to the test datasets.

The average accurate rates based on all the test datasets are shown in Tables III and IV for corn and soybeans, respectively. The accurate rates are shown in this way: at pre-planting for corn, for instance, $67.4 \%$ of the observations are correctly assigned into the low risk group based on the model, while $63.1 \%$ are correctly assigned into 
Table III. Average accurate rates of the risk assessments for the three kinds of test datasets for corn

\begin{tabular}{llcc}
\hline Stages & Groups & $\begin{array}{c}\text { Correct rates of } \\
\text { each group }(\%)\end{array}$ & $\begin{array}{c}\text { Average accurate } \\
\text { rates of each stage }\end{array}$ \\
\hline Pre-planting & Low risk & 67.4 & 65.3 \\
& High risk & 63.1 & 73.9 \\
Stage1 & Low risk & 79.4 & 84.3 \\
Stage2 & High risk & 68.4 & \multirow{2}{*}{89.0} \\
& Low risk & 85.5 & \\
Stage3 & High risk & 83.2 & 89.5 \\
& Low risk & 88.3 & \\
Stage4 & High risk & 89.7 & \\
& Low risk & 86.7 & \\
& High risk & 92.3 & \\
\hline
\end{tabular}

the high risk group. Therefore, the average possibility to correctly classify observations for corn at pre-planting is $65.3 \%$.

It was not a surprise that the accurate rates are lower at pre-planting than they are during the later stages, because future weather during the growing season is uncertain at this time. However, there is an about $65 \%$ possibility to successfully assess drought risk on dryland corn yield prior to the growing season, indicating that preplanting weather does have an impact on corn's final yield. Some researchers forecasted yield at very early growth stage using "combined information," which was the actual pre-planting weather data combined with the historical growing season weather data, or combined with the growing season weather forecast data (Luo et al., 1994; Duchon, 1986). Using weather data for pre-planting alone to assess drought risk on the crop's final yield has not been reported. The results of this study reveal that it is possible to assess drought risk on corn yield using weather information prior to the growing season.

Generally, the accurate rates increase as the growth stages progress for corn. At stage 2 , the average rate for the high and low risk classifications reaches $84.3 \%$. The possibility increases to $89 \%$ at stage 3 and increases slightly to $89.5 \%$ by stage 4 . This indicates that weather in the last growth stage plays only a minor role in the risk assessment because corn that is near to maturity does not respond to water stress as much as it did during previous stages.

Like corn, the accurate rates of soybeans increase as the crop develops. However, the accurate rates in both the high and low risk classifications of soybeans are lower than that of corn at all the stages, indicating the relationship between soybean yield 
Table IV. Average accurate rates of the risk assessments for the three kinds of test datasets for soybeans

\begin{tabular}{llcc}
\hline Stages & Groups & $\begin{array}{c}\text { Correct rates of } \\
\text { each group (\%) }\end{array}$ & $\begin{array}{c}\text { Average accurate } \\
\text { rates of each stage }\end{array}$ \\
\hline Pre-planting & Low risk & 48.5 & 57.1 \\
Stage1 & High risk & 65.8 & 63.6 \\
Stage2 & Low risk & 54.0 & \\
& High risk & 73.3 & 64.0 \\
Stage3 & Low risk & 65.8 & 77.5 \\
& High risk & 62.2 & \\
Stage4 & Low risk & 81.7 & 85.3 \\
& High risk & 73.3 & \\
Stage5 & Low risk & 85.6 & 85.9 \\
& High risk & 85.1 & \\
\hline
\end{tabular}

and weather at earlier growth stages is not as close as corn. In other words, soybeans have the capacity to recover from water stress.

To provide a better visualization of the agricultural drought risk assessment, the results were presented in a GIS. To create a state risk assessment map, three data layers were required: a map of Nebraska county boundaries, a map of leading counties in crop harvesting, and a map of assessment results of each county with two classes: high and low risk. These data layers were processed and then combined to produce one coverage in ArcMap within ArcGIS 8.2 (Environmental Systems Research Institute, Inc.).

The risk assessment maps for corn in 1974 are shown in Figure 3. Counties in white on the maps mean no, or minimal, dryland corn acres were planted. The numbers appearing on the counties denote actual corn yield residuals for 1974. As defined previously, a county experiences a high agricultural drought risk if its yield residual is below -0.5 . The calculated yield residuals of 1974 were all below -0.5 , indicating corn yields of all the leading counties belonged to the high risk group in this year. Counties in gray were identified by the model to have low risks on dryland corn yield at a specific stage, while counties in dark gray were identified to have high risks on dryland corn.

As shown in Figure 3, at pre-planting (end of April), only ten of the leading counties are assigned into the high risk group. The accurate rate is only $24 \%$. At stage 1 (end of June), more counties are assigned into the high risk. The accurate rate increases to $43 \%$. At stage 2 (later July), all the counties in eastern and central 

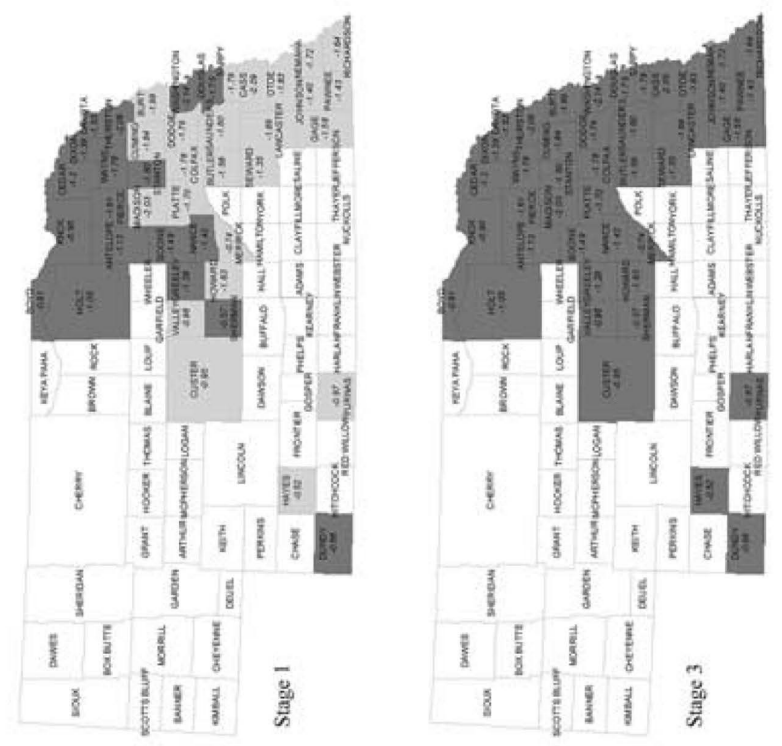

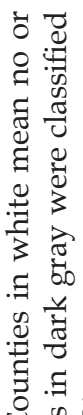

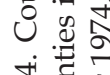

芯泀

.

हृ :

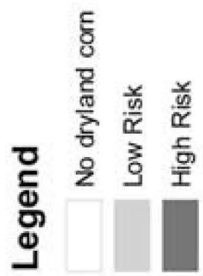

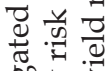

.

宅

눈.

+

焉免

拧

के :
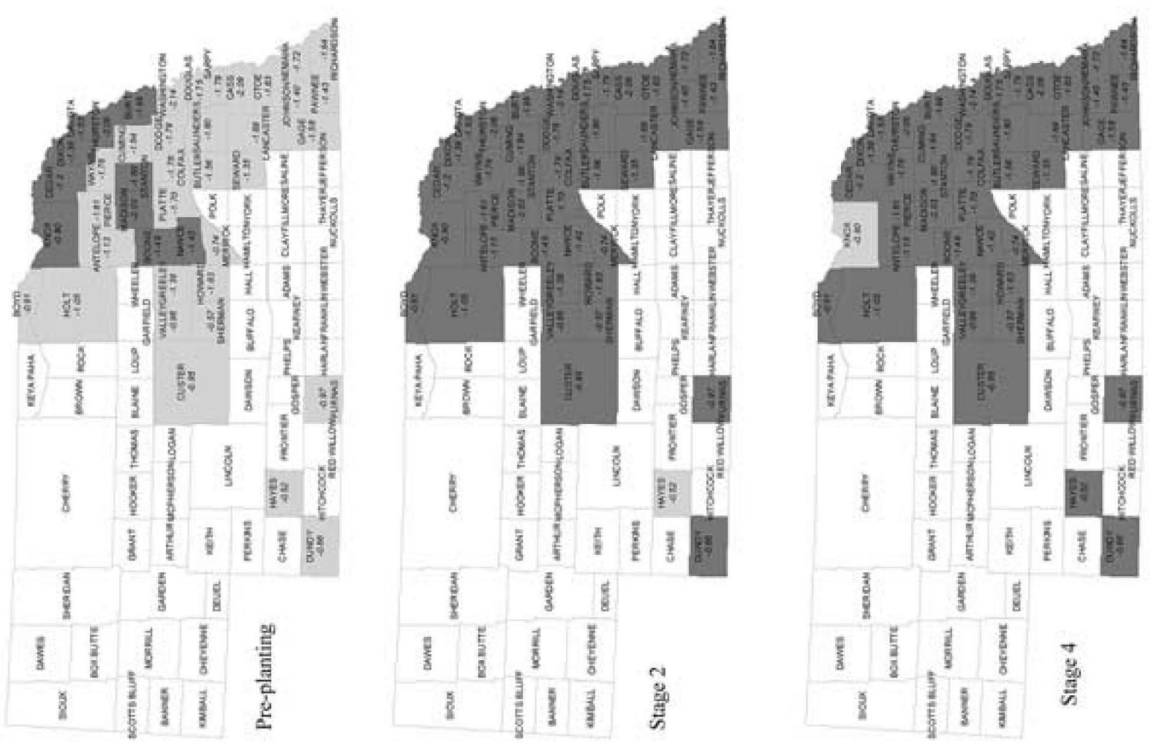

$\mp 8$

.

큼ำ

2.

능

\#U 0

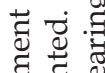

芷

क

范

की

䒕氙

ठ 트

¿ 8

중

可 $\cdot \vec{v}$

क⿺ 一)

ले चี

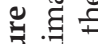

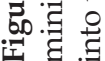


Nebraska are assigned into the high risk group and the accurate rate reaches $97.6 \%$. All the counties are assigned into the high risk group by stage 3 with a accurate rate of $100 \%$. At the last stage (end of September), the accurate rate is the same as it was at stage 2 .

Nebraska experienced a hot and dry growing season in 2002, which caused an agricultural loss of $\$ 1.2$ billion (IANR, 2003). Figure 4 shows the risk assessment maps from pre-planting to stage 4 for 2002. As indicated, the number of the counties in the high risk group increases with time and high risk areas spread from west to east. It can be seen that only a few counties on the northeastern corner of the State have low risks on corn yield in stage 2 and 3 (later July and August). By the end of September (stage 4), all the leading counties are assessed to have high risk except for Burt County, indicating that most of the leading counties in dryland corn planting are assessed to have high risks on corn yield in 2002. Thus, it can be concluded that corn yield of 2002 would be much lower than normal in most of the dryland-corn-planting counties due to the extreme drought. On the other hand, the risk assessment by the model for soybeans in 2002 was not as bad as that for corn. However, half of the leading counties in soybean planting in eastern Nebraska were shown to have had high agricultural drought risk.

The final 2002 yields became available online by the end of May 2003 while this article was being prepared. All 2002 county corn yield residuals were below -0.5 except for Thurston County, which had a yield residual of -0.41 .

\section{Summary}

An agricultural drought risk assessment model was developed for corn and soybeans on the basis of feature variables derived from the SPI and CSDI using multivariate techniques. This model can be used to assess real-time agricultural drought risk on specific crops at critical stages prior to and during the growing season by retaining previous, and adding current, weather information as the crop passes through the various growth stages. Based on the research and results of the analyses, the agricultural drought risk discriminant model presented in this study improves agricultural drought assessment in the following ways.

First, the model integrates two existing drought indices, the SPI and CSDI, because the SPI can be used to monitor drought over a wide spectrum of time scales (from 1week to a few yrs), which reflect the amount, timing and distribution of moisture supply before and during the growing season precisely; and because the CSDI links specific crop phenological information.

Second, the model uses pre-planting weather information as one of the periods to assess drought risk on final crop yield at the stage before crop is planted, providing a valuable indication of drought risk in sufficient time for policy makers.

Third, five stages for corn and six stages for soybeans are determined to be the critical stages to assess drought risk based on the statistics of actual crop phenological conditions. Once the model is put into operation, the risk assessment map 

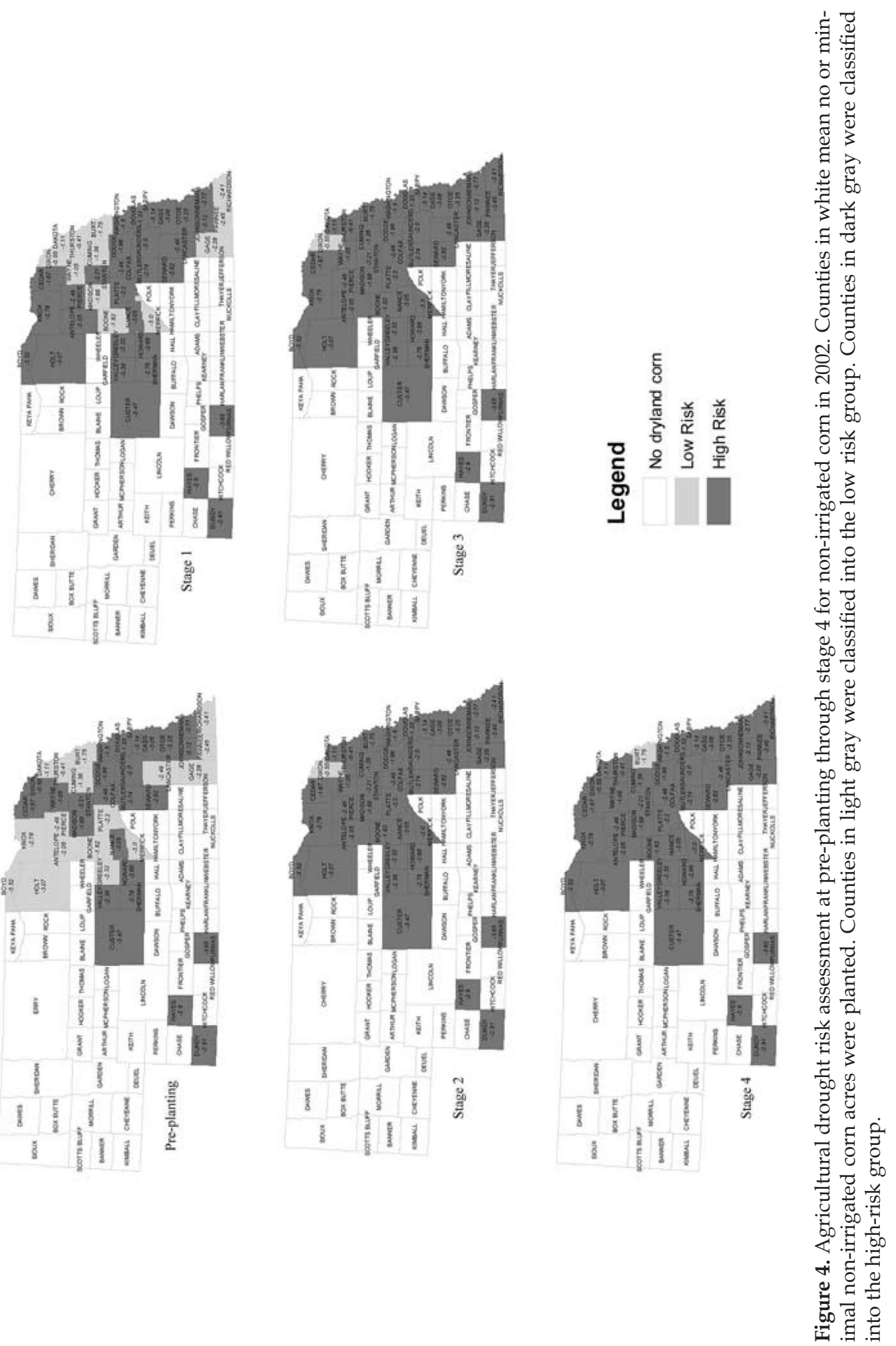
can be produced at the critical stages, providing information in a timely manner about potential agricultural drought risk on dryland crop yield for policy makers and others.

Fourth, the feature variables used in each stage are not static. As crop development progresses, variables that indicate the status of moisture supply conditions are added. At the same time, variables that describe moisture supply of previous stages are retained.

Fifth, this study sets up a framework to assess drought risk on crops on the basis of feature variables derived from drought indices. It is not necessary to use the indices employed and the exact growth stages defined in this study. For another region in which data is limited for calculating the indices and crop phenology is different from Nebraska, the drought indices that best fit this region can be used as substitutes, and growth stages that match crop phenological information in the region can be defined.

Sixth, drought risk assessment maps can be presented by combining the data layers in a GIS, providing a better visualization of agricultural drought risk assessment.

Additional research is needed to improve the operational assessment capability of this model. For example, it is necessary to extend the two groups to multiple groups, like non-, low-, moderate-and high-risk groups. It would also be useful to employ more sophisticated statistical multivariate techniques to detect the best feature variables and improve the accuracy of assessment. Remotely sensed data could also be included as a feature variable. Using weather information that more accurately represents the actual climate conditions in the area where the yield is obtained could improve assessment accuracy. Furthermore, it would be better to assess drought risk on a spatial resolution that is finer than the county level, because climate and crops vary within a county.

\section{References}

Agriculture Atlas of Nebraska: 1977, University of Nebraska Press, 110 pp.

Camargo, M. B. P. and Hubbard, K. G.: 1999, Drought sensitivity indices for a Sorghum Crop, Journal of Production Agriculture 12(2), 312-316.

CARC, Climate Assessment and Response Committee: 2002, http:/ / carc.nrc.state.ne.us/carcunl/

CCC, Colorado Climate Center: 2003, http://ccc.atmos.colostate.edu/standardizedprecipitation. $\underline{\text { shtml }}$

da Mota, F. S.: 1983, Weather-technology models for corn and soybean in the south of Brazil, Agricultural Meteorology 28, 49-64.

de Jager, J. M., Potgieter, A. B., and van den Berg, W. J.: 1998, Framework for forecasting the extent and severity of drought in maize in the Free State Province of South Africa, Agricultural Systems 57, 351-365.

de Jager, J. M., Howard, M. D., and Fouche, H. J.: 2000, Computing drought severity and forecasting its future impact on grazing in a GIS, In: D. A. Wilhite (ed.), Drought: A Global Assessment, Chap. 20, Routledge, London, pp. 269-278. 
Denmead, O. T. and Shaw, R. H.: 1960, The effects of soil moisture stress at different stages of growth on the development and yield of corn, Agronomy Journal 52, 272-274.

Dennett, M. D., Elston, J., and Diego Q, R.: 1980, Weather and yields of tobacco, sugar beet and wheat in Europe, Agricultural Meteorology 21, 249-263.

Dietz, T. J., Put, M., and Subbiah, S.: 1998, Drought risk assessment for dryland agriculture in semiarid Telangana, Andhra Pradesh, India, In: H. J. Bruins (ed.) The Arid Frontier: Interactive Management of Environment and Development, Chap. 8, Kluwer Academic Publishers, Dordrecht, Netherlands, pp. 143-161.

Duchon, C. E.: 1986, Corn yield prediction using climatology, Journal of Climate and Applied Meteorology 25, 581-590.

Easterling W. E., Warren, S. A. P., Guinan, P., and Shafer, M.: 1988, Improving the detection of agricultural drought: A case study of Illinois corn production, Agricultural and Forest Meteorology 43, 37-47.

Edwards, D. C. and McKee, T. B.: 1997, Characteristics of 20th century drought in the United States at multiple time scales, Atmospheric Science Paper No. 634, May, 1-30.

Germain, R. J.: 1996, Drought management using a geographical information system, M.S. Thesis, College of Engineering and Technology, Ohio University.

Hayes, M., Wilhite, D. A., Svoboda, M., and Vanyarkho, O.: 1999, Monitoring the 1996 Drought using the standardized precipitation index, Bulletin of the American Meteorological Society 80(3), 429-438.

Hayes, M., Svoboda, M., and Wilhite, D. A.: 2000, Monitoring drought using the standardized precipitation index, In: D. A. Wilhite (ed.), Drought: A Global Assessment, Chap. 1. Routledge, London, pp. 168-180.

HPRCC, High Plains Regional Climate Center: 2002, http://hprcc.unl.edu/

Hill, R. W., Johnson, D. R., and Ryan, K. H.: 1979, A model for predicting soybean yields from climate data, Agronomy Journal 71, 251-256.

IANR, Institute of Agriculture and Natural Resources, University of Nebraska - Lincoln, 2003. http://ianrnews.unl.edu/static/0301162.shtml

Johnson, R. A. and Wichern, D. W.: 1998, Applied Multivariate Statistical Analysis, 4th Edition. Prentice Hall, Upper Saddle River, New Jersey, 81 pp.

Kulshreshtha, S. N. and Klein, K. K.: 1989, Agricultural drought impact evaluation model: A systems approach, Agricultural System 30, 81-96.

Kumar, V. and Panu, U.: 1997, Predictive assessment of severity of agricultural droughts based on agro-climatic factors, Journal of the American Water Resources Association 33(6), 1255-1264.

Lourens, U. W. and de Jager, J. M.: 1997, A computerized crop-specific drought monitoring system: Design concepts and initial testing, Agricultural System 53, 303-315.

Luo, H., Skees, J. R., and Marchant, M. A.: 1994, Weather information and the potential for intertemporal adverse selection in crop insurance, Review of Agricultural Economics 16(3), 441-451.

McKee, T. B., Doesken, N. J., and Kleist, J.: 1993, The relationship of drought frequency and duration to time scales, Proceedings of the Eighth Conference on Applied Climatology, Boston: American Meteorological Society, pp. 179-184.

Meyer, S. J., Hubbard, K. G., and Wilhite, D. A.: 1993a, A crop-specific drought index for corn: I. Model development and validation, Agronomy Journal 86, 388-395.

Meyer, S. J., Hubbard, K. G., and Wilhite, D. A.: 1993b, A crop-specific drought index for corn: II. Application in drought monitoring and assessment, Agronomy Journal 86, 396-399.

Meyer, S. J. and Hubbard, K. G.: 1995, Extending the crop-specific drought index to soybean, 9th Conference on Applied Climatology, American Meteorological Society, pp. 258-259.

Mjelde, J. W. and Penson Jr., J. B.: 2000, Dynamic aspects of the impact of the use of perfect climate forecasts in the corn belt region, Journal of Applied Meteorology 39, 67-79. 
NASS, USDA, U. S. Department of Agriculture: 2003, http://www.usda.gov/nass/

NDMC, National Drought Mitigation Center: 2003, http://www.drought.unl.edu/monitor/spi. $\underline{\mathrm{htm}}$

NDMC/NOAA/USDA Drought Monitor: 2003, http://www.drought.unl.edu/dm/monitor.html

Nullet, D. and Giambelluca, T. W.: 1988, Risk analysis of seasonal agricultural drought on Low Pacific Islands, Agricultural and Forest Meteorology 42(2-3), 229-239.

Pitter, R. L.: 1977, The effect of weather and technology on wheat yields in Oregon, Agricultural Meteorology 18, 115-131.

Pochop, L. O., Cornia, R. L., and Becker, C. F.: 1975, Prediction of winter wheat yield from shortterm weather factors, Agronomy Journal 67, 4-7.

Redmond, K. T.: 2002, The depiction of drought: A Commentary, The Bulletin of the American Meteorological Society 83(8), 1143-1147.

Reibsame, W. E., Changnon, Jr., S. A., and Karl, T. R.: 1991, Drought and Natural Resources Management in the United States: Impacts and Implications of the 1987-89 Drought, Westview Press, Boulder, Colorado, 174 pp.

The State of Nebraska Drought Mitigation and Response Plan: 2002, http://carc.nrc.state.ne.us/ carcunl/docs/planning.html

Sundt, N.: 2002, Agriculture and climate change: A hard row to hoe, http://www.globalchange. org/featall/2000winter2.htm

Starr, T. B. and Kostrow, P. I.: 1978, The response of spring wheat yield to anomalous climate sequences in the United States, Journal of Applied Meteorology 17(8), 1101-1115.

Svoboda, M., LeComte, D., Hayes, M., Heim, R., Gleason, K., Angel, J., Rippry, B., Tinker, R., Palecki, M., Stooksbury, D., Miskus, D., and Stephens, S.: 2002, The drought monitor, The Bulletin of the American Meteorological Society 83(8), 1181-1190.

Thompson, D. and Powell, R.: 1998, Exceptional circumstances provisional in Australia - is there too much emphasis on drought? Agricultural Systems 57(3), 469-488.

Thompson, D. R. and Wehmanen, O. A.: 1979, Using Landsat digital data to detect moisture stress, Photogrammetric Engineering and Remote Sensing 45(2), 201-207.

Thompson, L. M.: 1988, Effects of changes in climate and weather variability on the yields of corn and soybeans, Journal of Production Agriculture 1, 20-27.

Walker, G. K.: 1989. Model for operational forecasting of western Canada wheat yield, Agricultural and Forest Meteorology 44, 339-351.

WRCC, Western regional Climate Center: 2003, http://www.wrcc.dri.edu/spi/spi.html

Wilhelmi, O.: 1999, Methodology for assessing vulnerability to agricultural drought: A Nebraska case study, Ph.D. Dissertation, University of Nebraska-Lincoln, $136 \mathrm{pp}$.

Wilhelmi, O. and Wilhite, D. A.: 2002, Assessing vulnerability to agricultural drought: A Nebraska case study, Natural Hazards 25, 37-58.

Wilhite, D. A.: 1982, Measuring Drought Severity and Assessing Impact, International Symposium on Hydrometeorology, American Water Resources Association.

Wilhite, D. A. and Neild, R. E.: 1982, Determining drought frequency and intensity on the basis of plant response: Wild hay in the sand gills of Nebraska, U.S.A. Agricultural Meteorology 25, 257-265.

Wilhite, D. A.: 1992, Drought, Encyclopedia of Earth System Science 2, 81-92.

Wilhite, D. A.: 2000, Reducing societal vulnerability to drought, In: D. A. Wilhite (ed.), Drought: A Global Assessment, Chap. 51, Routledge, London, pp. 295-298.

Wu, H.: 2002, Agricultural drought risk assessment: An operational model for Nebraska, Ph.D. dissertation, University of Nebraska-Lincoln, $127 \mathrm{pp}$.

Xu, M.: 1996, Wheat grain quality as related to climate: Evaluation and model development, Ph.D. dissertation, University of Nebraska-Lincoln Dissertation, 121 pp. 